\title{
Reduced Mass Flux due to Mixing in Controlled Exchange Flows with Possible Applications to The Indonesian Through-Flow
}

\author{
Tjipto Prastowo* \\ Jurusan Fisika, FMIPA, Universitas Negeri Surabaya
}

\begin{abstract}
The Indonesian Through-Flow (ITF) is a system of surface ocean currents flowing from the western Pacific Ocean through numerous straits and sills within the eastern Indonesian seas into the Indian Ocean. The ITF carries a large amount of heat and water affecting climate on regional and global scales. A more detailed, comprehensive study by either direct measurements, numerical simulations or laboratory experiments is then needed to fully understand the flow. In this context, laboratory experiments are used to study the characteristics of mixing in density-driven exchange flows, so as to examine similar situations occurring in the flow. The experiments have also particular relevance to improving predictions of mixing in deep overflows, as well as to understanding the dynamics of exchange flows between water bodies such as estuaries, marginal seas and the open ocean. Vigorous turbulence which leads to irreversible mixing is observed in the experiments and the resulting reduction in exchange flux is measured to be $82 \%$ of the maximal exchange predicted by hydraulic theory. The possible application of the experimental results to Indonesian sea settings is also discussed as the results are relevant to physical oceanographic problems in the Indonesian waters.
\end{abstract}

KEYWORDS: mixing, exchange flows, flux reduction

\section{INTRODUCTION}

Density-driven exchange flows through topographic constrictions that connect two bodies of water with different densities occur in many geophysical situations. Such constrictions include straits and sills, and affect flows in both the abyssal oceans and relatively marginal seas. In many cases, the rate of exchange of water and heat is hydraulically controlled by the dynamics of stratified flow in the straits or over the sills. This control of mass flux has a large influence on heat and salt fluxes between parts of the oceans, and thus affects regional climate.

One major oceanographic problem associated with densitydriven exchange flows is the Indonesian Through-Flow (ITF). The ITF carries water from the western Pacific Ocean to the Indian Ocean through a series of straits in the Indonesian Archipelago. It transports south through the Indonesian straits a large amount of heat and water from the warm surface waters of the western Pacific Ocean, and contributes to the coupling between ocean and atmosphere in the Pacific and Indian Ocean regions.

The ITF plays a key role in the heat and freshwater balances of the upper layer of the Pacific and Indian Oceans. Changes in magnitude of the Throughflow can affect patterns of heat exchange with the atmosphere in regions that are remote from the Indonesian straits. In turn, these altered heat fluxes result in a change in the coupled ocean-atmosphere model. Thus it

*E-MAIL: tjipto.prastowo@gmail.com is important to develop a greater understanding of the ITF in order to help assess how the flow affects climate on both the regional and global scales.

Many authors [1-4] agree that the Throughflow is a predominantly North Pacific origin and that the Throughflow has a strong temporal variability at various time scales ranging from seasonal to interannual [5-8]. One important aspect of the ITF is its impact on the biological environment. Gordon et al. [9] argued that the ITF is almost two dimensional in the upper layer of the ocean. However, at greater depth there are significant vertical motions due to numerous sills encountered, leading to density-driven overflows. These overflows will, in turn, force water within the confined basins to be displaced vertically. Such a process maintains the properties of the confined water masses (e.g., temperature and salinity distributions, dissolved gases, and nutrients) in the local region implying a biological balance between the upper layer and the deeper waters. Thus vertical mixing in the straits of the Indonesian Archipelago is of great importance, and hence a better understanding of this process is required to predict the water properties more accurately.

However, the dynamics of the ITF is not fully understood from both observational and theoretical viewpoints. Estimates of the mass transport are still uncertain, partly due to the difficulty of making simultaneous and continuous measurements in the complex bathymetry of the Indonesian seas. Observational studies $[10,11]$ show a wide range of estimates, 2-20 Sv for the magnitude of the Throughflow (Figure 1), implying a large uncertainty in the variability of the Throughflow. Recent ocean circulation models $[12,13]$ have also been used to study the transport variability of the Troughflow but still unable to adequately resolve the variability of the flow. Wijffels et al. 


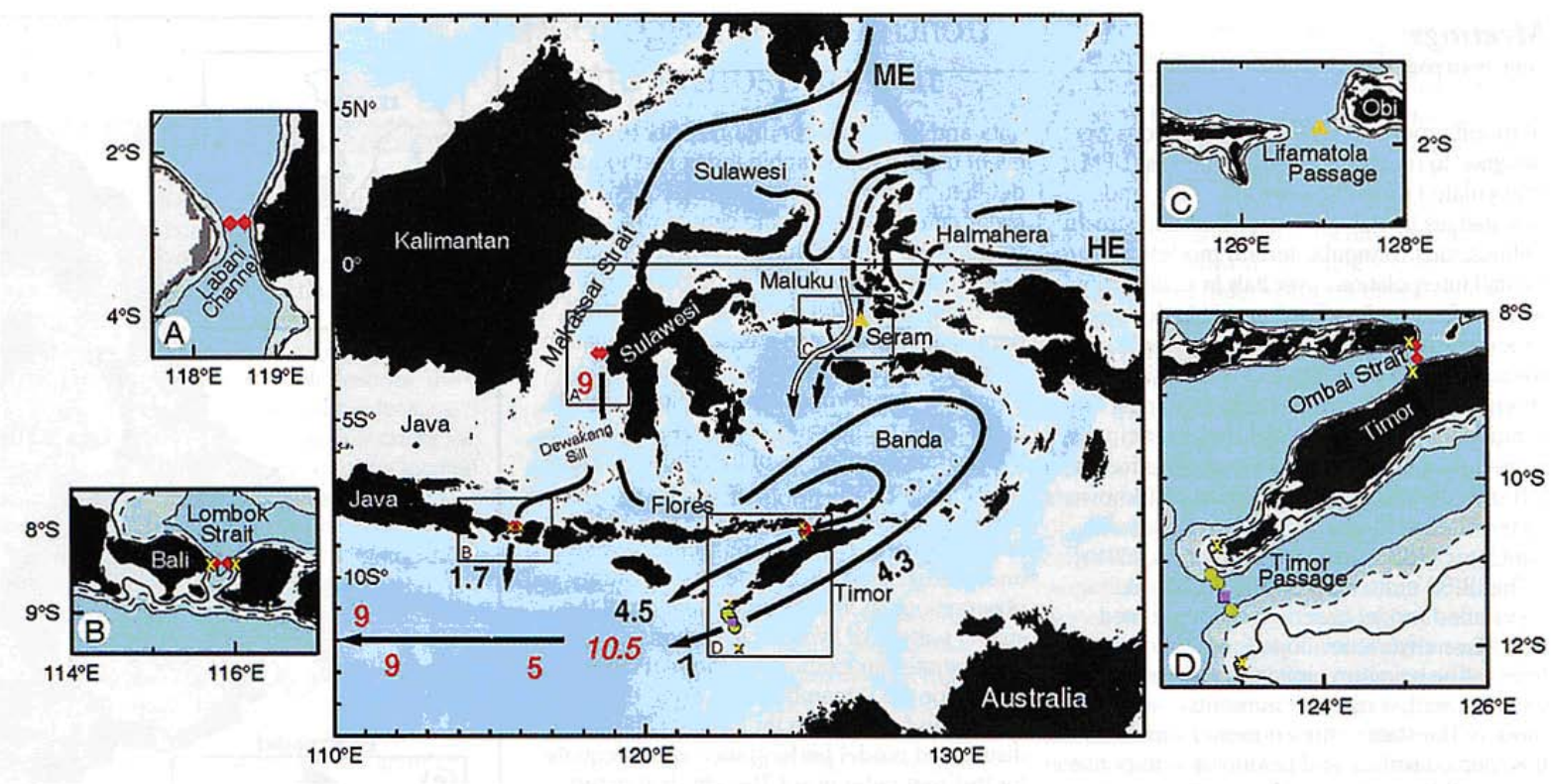

FIG. 1: Possible routes of the Indonesian Through-Flow and its volume transport (taken from EOS, American Geophysical Union, Vol. 85, No. 39, September 2004)

[14] argued that variation in the ITF transport is the dominant source of errors in the basin wide heat and freshwater budgets for both the Pacific and Indian Oceans.

In this study, we present the dynamics of throughflow processes in the oceans using laboratory experiments. These experiments are used to examine exchange flows with mixing. A parallel development of a theoretical flow description will be an important element for the results to be applied to a range of specific ocean flows, such as those in the Indonesian waters. The results will also add to fundamental understanding of the fluid dynamics of stratified flows.

\section{BACKGROUND}

Exchange flows through a constriction depend on the density difference across the constriction, the fluid properties, and the nature of the topographic constriction. These flows are commonly represented by two counter flowing layers, each having constant density and velocity [15]. Internal hydraulic theory provides a useful tool to predict maximal exchange in the two-layer approximation [16]. The hydraulic solution relies on the assumptions that flow is steady, inviscid, incompressible, hydrostatic, and non-rotating $[17,18]$.

The quantity of interest in most environmental exchange flows is the maximal exchange flux. The usefulness of the hydraulic theory in predicting the maximal exchange of both volume and mass through the constriction has been discussed in several papers $[19,20]$. Given some simple external parameters, such as the density contrast across the constriction, the minimum width $\Delta \rho$ of the constriction, and the total depth $\mathrm{b}_{\circ}$ of the water, one can predict an upper bound on the volume flux in one layer and net mass flux as

$$
\begin{array}{r}
Q=\frac{1}{4} b_{\circ} \sqrt{g^{\prime}} H^{\frac{3}{2}} \\
M=\frac{1}{4} \Delta \rho b_{\circ} \sqrt{g^{\prime}} H^{\frac{3}{2}}
\end{array}
$$

When there is significant vertical transport of mass and momentum or internal mixing between layers, the exchange is less than the maximal predictions given above.

Recently, there has been increasing interest in exchange flows with mixing through a topographic constriction. Several authors have addressed the role of mixing in exchange flows and raised the issue of flux reduction attributed to mixing across density interfaces. These include laboratory experiments [21], numerical investigations [19, 22, 23] and field observations [24].

\section{EXPERIMENTS}

We carry out a laboratory study of mixing in an exchange flow through a contracting channel at the Geophysical Fluid Dynamics Laboratory in the Research School of Earth Sciences, The Australian National University. Experiments have been conducted in a long, flat-bottomed tank, which allows visualisation of the flow. An acrylic constriction is placed at the centre of the channel to model a strait (see Figure 2).

To run the experiment, we fill the tank with two fluids of different densities, and place a sliding gate in the middle of the tank. Once the gate is withdrawn, the density-driven exchange flow of salt and freshwater occurs, leading to shear instability and extensive mixing particularly in the vicinity of the constriction. Kelvin-Helmholtz (KH) billows grow on the 


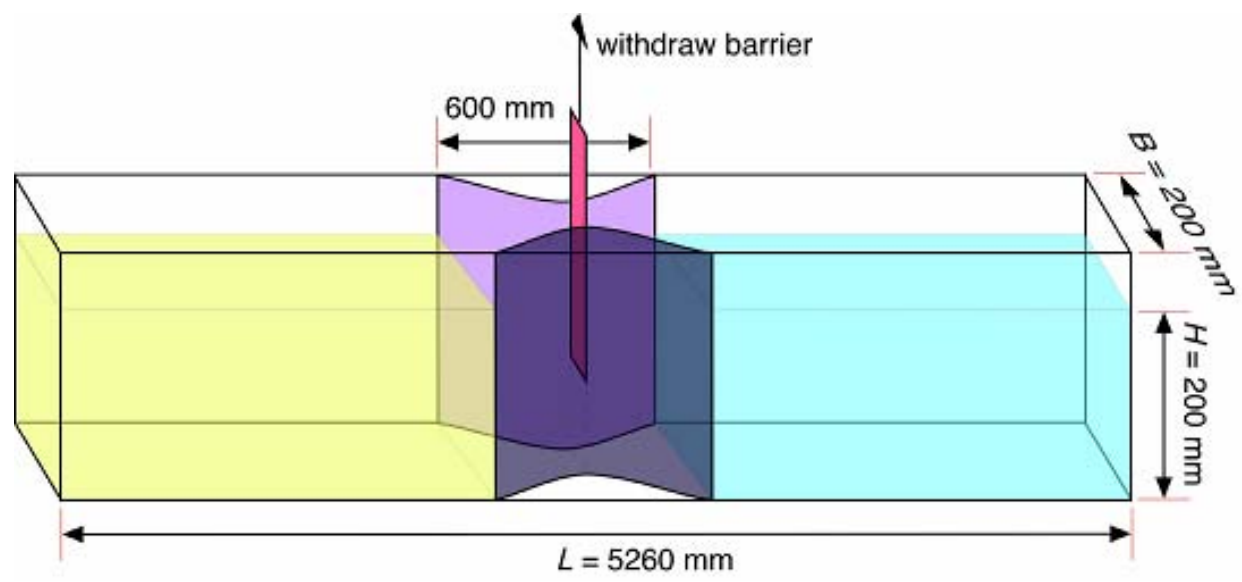

FIG. 2: A contracting channel for an experimental use of exchange flows

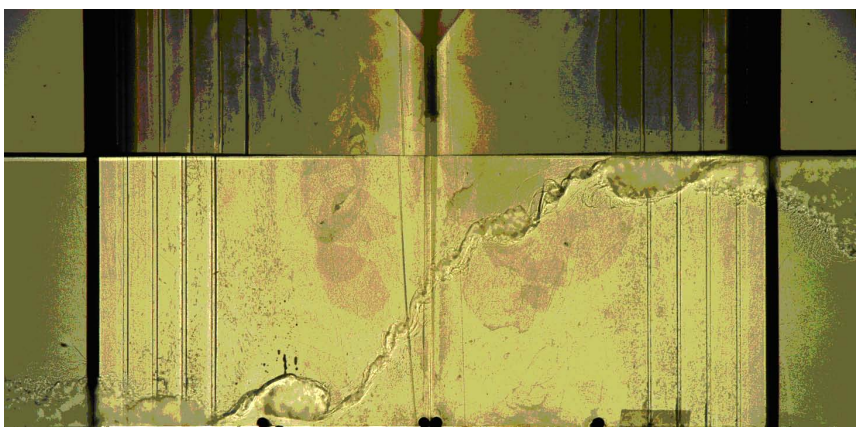

FIG. 3: Intense mixing in the vicinity of the constriction leading to KH billows.

strongly sheared interface within the constriction, generating overturns and vertical mixing between the salt and freshwater layers. These billows grow to large amplitude and then collapse, after which the mixed fluid is advected by the flow away from the constriction.

Exchange flows through a contracting channel that connects waters of different properties are subject to friction at the bottom, sidewalls, and the interface between the layers. Such frictional effects will reduce the rate of exchange. Pratt [25] suggested that bottom friction is likely to be important for long and shallow straits while in short and deep straits such an effect is likely to be negligible. In our experiments, the influence of friction and internal mixing on the exchange flow is included in theoretically simple volume and mass flux formulations below,

$$
\begin{aligned}
q & \leq 0,875 \\
m & \leq 0,875
\end{aligned}
$$

These give us an upper bound for both the volume and mass fluxes in exchange flows under the influence of both mixing and friction.

\section{RESULTS}

We present final density profiles in order to illustrate the characteristics of density profiles in adjacent basins after the experiment. These profiles are used in the calculation of mass fluxes and mixing efficiencies.

It can be seen from Figure $4(a, b)$ that there is no significant mixing in regions close to the bottom or near the surface, so that the water properties in these two regions are almost unchanged. Instead, mixing regions are supposed to be at some depth from the surface. The similarity of the density profiles in the two figures suggests that the basic mixing processes in the rundown case are independent of the density difference and the constriction width. It was found that the observed mass flux is approximately $82 \%$ of the hydraulic prediction. This suggests that the observed mass flux does not depend on the density difference but may depend weakly on the constriction width. There may be a small effect of friction on the observed mass flux.

\section{DISCUSSION}

The laboratory experiments presented here demonstrate several interesting features associated with the flux reduction. Measurements of the net mass flux in the exchange flow through a topographic constriction provide good agreement with previous work using both laboratory experiments and numerical investigations. The results of the experiments compare well with the prediction for mass flux reduction. This suggests that sidewall and bottom friction are likely to have a little or no effect on the exchange flow. The density profiles (Figure 4) suggest that mixing regions in both the open sea and relatively shallow waters lie in some depth below the surface. Waters near the surface and at the bottom have the same properties as the original sources. This knowledge can be used to estimate to some extent thermocline depth associated with mixing regions in the ocean - the most possible places to find marine food web, and hence fish. Vertical mixing acts in a similar manner to upwelling processes, which bring deep and 


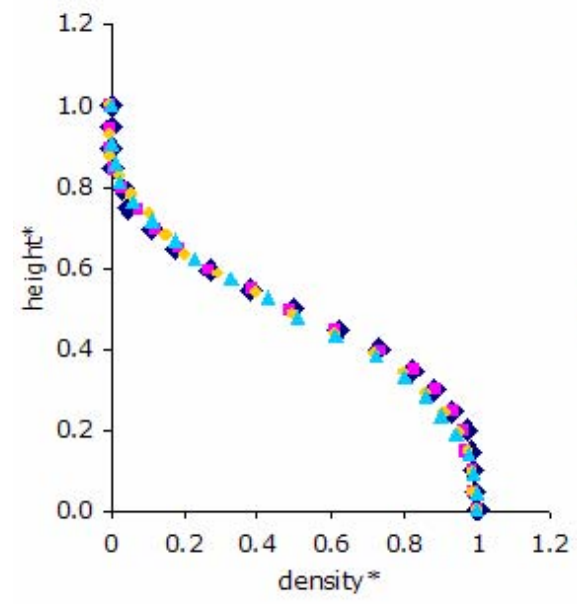

(a)

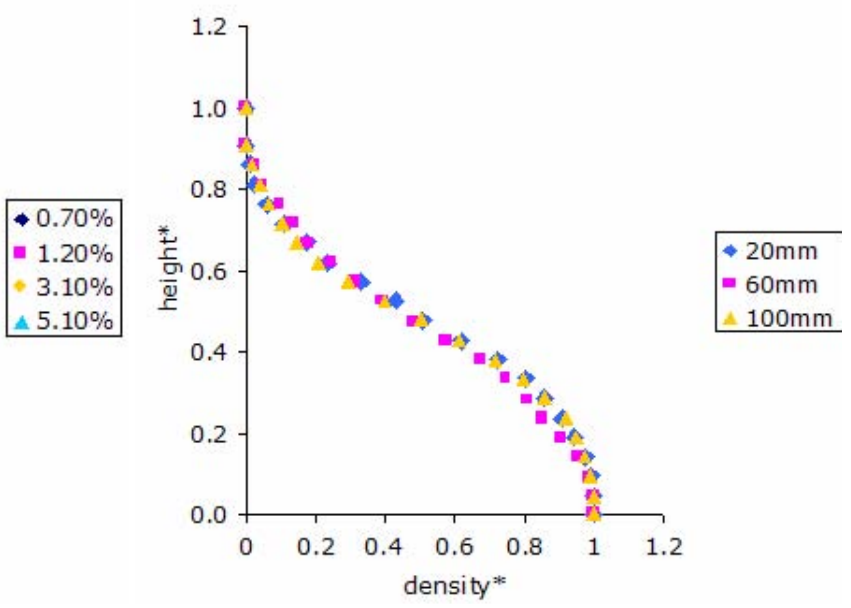

(b)

FIG. 4: (a) Final density profiles of the rundown case for four different $\Delta \rho$, (b) Final density profiles of the rundown case for three different $\mathrm{b}_{\circ}$.

cold, nutrient-rich waters near the surface where phytoplankton begins to grow as sunlight and natural foods are available. Wherever mixing takes place in the ocean, the surface waters will be enriched with additional nutrients required to initiate and maintain the ocean food chain. Thus it is clear that the properties of sea water is related to both physical and biological processes in the ocean.

As part of the global conveyor belt of the world ocean, the ITF plays a key role in regulating climate and rainfall across Indonesian regions. This is a considerably significant factor where severely natural events frequently occur in Indonesian areas. For Indonesia, understanding the ITF will enable the government to make well-prepared management decisions, concerning with agricultural, water and fisheries issues as well as climate-related natural disasters (e.g. floods, droughts and forest fires). The authority of the Indonesian Agency for Marine and Fisheries says that measurements of mixed water in the Flores and Banda Seas will provide a better understanding of such a process, which in turn maintains the properties of the water in the Seas, and hence fisheries stocks (www.marine.csiro.au).

In response to this, an international team of scientists from five countries (Indonesia, Australia, United States, France and Netherlands) established INSTANT (International Nusantara Stratification and Transport), a regional ocean monitoring program within Indonesian seas. This program includes the deployment of a series of moored instruments to directly measure sea-level and in situ temperature, velocity and salinity of the ITF at full depth. First moorings were already initiated in August 2003 using the Australian Research-Vessel (RV) Southern Surveyor, which will be followed by the second deployment in June 2005 using the Indonesian RV Baruna Jaya.

An interesting research of upwelling processes in relation to abundance of chlorophyll and fish catches in some coastal areas of the Indonesian seas was carried out by Hendiarti et al. [26]. During South-East (SE) monsoon from July to September 2001, they observed that upwelling occurring along the southeast of Java coastline brings nutrient-rich water from the deeper layer of the Sea into photic zone. In this zone, phytoplankton begins to grow as sunlight is available. They found that in places where upweling occurs, chlorophyll concentrations are high maintaining the distribution and growth of phytoplankton, hence zooplankton and pelagic fish.

However, they did not investigate mixing and upwelling processes in eastern Indonesian seas, such as the Banda Sea where it is believed to be the place for seasonal wind-induced upwelling [1]. As discussed earlier, the Banda Sea appears to act as a mixing region between warm less saline ITF surface waters of North Pacific origin and deeper water masses of South Pacific origin. The Banda Sea also controls the bulk of ITF water, flowing through the Strait of Makassar and spending some time on mixing in the Sea before curling southward into the eastern Indian Ocean through Timor passages. Thus, a fully comprehensive understanding of the eastern Indonesian seas is of great importance. This can be achieved by either observational studies through the INSTANT program, numerical investigations through a series of simulations or laboratory experiments through an approach of geophysical fluid dynamics.

\section{CONCLUSION}

A laboratory study of mixing in exchange flows through a contracting channel that connects two reservoirs of water with different densities is presented. In general, changes in the characteristics of water masses in the constricted channel occur through internal mixing, the process which may also occur in the eastern Indonesian seas. Existing internal hydraulic theory has been used to predict the maximal two layer exchange flux expected in the channel. The theory has also been extended to accommodate the effect of internal mixing on the flow. The most obvious effect of the mixing in the exchange flow is to reduce the horizontal transport compared with the hydraulic prediction. There is good agreement between the 
current research and previous work. Both confirm that the horizontal flux decreases as the intensity of vertical mixing increases. The reduction in net mass flux may be weakly dependent upon the constriction width, and was found to be around $82 \%$ of the maximal exchange based on the idealized hydraulic solution.

However, much remains to be understood about mixing in stratified exchange flows despite continual improvements in measurement techniques in the laboratory. The observed time dependence of the mixing efficiency, for example, remains unexplained. As thought to occur in The ITF where the exchange is largely in one direction, a mean flow can also be added in future work. This represents barotropic forcing, which is likely to exist in real cases (compared with the current research, purely baroclinic exchanges). In order to improve understanding of the physical processes in the ocean that can benefit to Indonesia in terms of economic values, such as agricultural products and fisheries stocks particularly in the eastern Indonesian seas, we need to know about the net effect of mixing on sea-air fluxes and its efficiency. Two promising suggestions in relation to this are made. Firstly, further and inten- sive research on oceanography which relates to environmental processes in the ocean is required to predict the quality of water within the Indonesian seas more accurately. Secondly, the Banda Sea and its surrounding seas must be taken into account in the research since they may give a solution to the government in improving low income rates among Indonesians.

\section{Acknowledgments}

The author is supported by an AusAID scholarship for the doctorate degree in Research School of Earth Sciences (RSES), The Australian National University (ANU). This research is part of the PhD project, and is mainly based on a mid-term report submitted to the Postgraduate Convenor of The University. The author would like to thank supervisor Prof. Ross Griffiths, co-supervisors Dr. Graham Hughes and Dr. Andy Hogg for their best guidance and support, Tony Beasley and Brad Ferguson for their technical assistance during the work.
[1] Ffield, A. and Gordon, A. L., Journal of Physical Oceanography, 22, 184-195 (1992)

[2] Godfrey, J. S., Hirst, A. C. and Wilkin, J., Journal of Physical Oceanography, 23, 1087-1098 (1993).

[3] Nof, D., Journal of Physical Oceanography, 25, 1369-1383 (1995).

[4] Hautala, S. L., Reid, J. L. and Bray, N. A., Journal of Geophysical Research, 101 (C5), 12375-12389 (1996).

[5] Bray, N. A., Hautala, S., Chong, J., and Pariwono, J., Journal of Geophysical Research, 101, 12239-12254 (1996).

[6] Meyers, G., Journal of Geophysical Research, 101 (C5), 1225512263 (1996).

[7] Hautala, S. L., Sprintall, J., Potemra, J. T., Ilahude, A. G., Chong, J. C., Pandoe, W. W. and Bray, N., Journal of Geophysical Research, 106 (C5), 19527-19546 (2001).

[8] Sprintall, J., Potemra, J. T., Hautala, S. L., Bray, N. A. and Pandoe, W. W., Temperature and salinity variability in the exit passages of the Indonesian Throughflow, Deep-Sea Research II, 50, 2183-2204, 2003.

[9] Gordon, A. L., Giulivi, C. F. and Ilahude, A. G., Deep topographic barriers within the Indonesian seas, Deep-Sea Research II, 50, 2205-2228, 2003.

[10] Gordon, A. L. and McClean, J., Journal of Physical Oceanography, 29, 198-216 (1999).

[11] Vranes, K., Gordon, A. and Ffield, A., The heat transport of the Indonesian Throughflow and implications for the Indian Ocean heat budget, Deep-Sea Research II, 49, 1391-1410, 2002.

[12] Lebedev, K. V. and Yaremchuk, M. I., Journal of Geophysical Research, 105 (C5), 11243-11258 (2000).
[13] Wajssowicz, R. C., Gordon, A. L., Ffield, A. and Susanto, R. D., Estimating transport in Makassar Strait, Deep-Sea Research II, 50, 2163-2181, 2003.

[14] Wijffels, S., Toole, J. and Davies, R., Journal of Geophysical Research, 106, 19481-19514 (2001).

[15] Armi L., Journal of Fluid Mechanics, 163, 27-58 (1986).

[16] Dalziel, S. B., Journal of Fluid Mechanics, 223, 135-163 (1991).

[17] Lawrence, G. A., Journal of Fluid Mechanics, 215, 457-480 (1990).

[18] Zhu, D. Z. and Lawrence, G. A., Journal of Hydraulic Engineering, 126, 921-928 (2000).

[19] Hogg, A. M., Ivey, G. N. and Winters, K. B., Journal of Geophysical Research, 106 (C1), 959-972 (2001).

[20] Ivey, G. N., Stratification and mixing in sea straits, Deep-Sea Research II, 51, 441-453, 2004.

[21] Helfrich, K. L., Journal of Physical Oceanography, 25, 359-373 (1995).

[22] Winters, K. B. and Seim, H. E., Journal of Fluid Mechanics, 407, 265-290 (2000).

[23] Stenstrm, P., Journal of Geophysical Research, 108 (C8) (2003).

[24] Bray, N. A., Ochoa, J. and Kinder, T. H., Journal of Geophysical Research, 100, 10755-10776 (1995).

[25] Pratt, L. J., Journal of Physical Oceanography, 16, 1970-1980 (1986).

[26] Hendiarti, N., Siegel, H. and Ohde, T., Investigation of different coastal processes in Indonesian waters using SeaWiFS data, Deep-Sea Research II, 51, 85-97, 2004. 